DOI: https://doi.org/10.47405/mjssh.v5i7.439

\begin{tabular}{|c|c|}
\hline 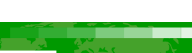 & Malaysian Journal of Social Sciences and Humanities (MJSSH) \\
\hline Malaysian Journal of & Volume 5, Issue 7, July 2020 \\
\hline $\begin{array}{l}\text { Humantites } \\
\text { (MJ - sSH) }\end{array}$ & e-ISSN : 2504-8562 \\
\hline & $\begin{array}{l}\text { Journal home page: } \\
\text { www.msocialsciences.com }\end{array}$ \\
\hline
\end{tabular}

\title{
Autonomous Orientation Behaviors Influence Towards Ex-Juvenile Entrepreneurs Delinquent Behavioral Change in Katsina State, Nigeria: A Conceptual Paper
}

\author{
Bilyaminu Usman', Sharizal Bin Hashim1, Jeff Lamptey', Ashemi Baba Ali² \\ ${ }^{1}$ Faculty of Economics and Business, Universiti Malaysia Sarawak (UNIMAS) \\ 2Department of Economics, University of Maiduguri, Borno State, Nigeria \\ Correspondence: Bilyaminu Usman (bilyaminu1974@gmail.com)
}

\begin{abstract}
Recent Entrepreneurship orientation autonomous dimension discussion revealed the important and the positive influence of autonomous orientation as one of the Entrepreneurial orientations (EO) towards organizational performance and profitability. However, discussion of autonomous orientation in the context of individual such as entrepreneurs behavioral change impact still silent, especially in the context of ex-juvenile entrepreneur that can give an insight to the Entrepreneurship body of knowledge. Therefore, the objective of this conceptual paper is to understand the influence of autonomous orientation behaviors as one of the individual entrepreneurial orientation (IEO) towards delinquent behavioral change of ex-juvenile entrepreneurs. The conceptual paper proposed the framework that exjuvenile entrepreneurs could be autonomous and more importantly autonomous orientation might have a positive influence towards ex-juvenile entrepreneurs' delinquent behavioral change. Subsequently relating development of this concept, the conceptual review demonstrates the importance of the autonomous orientation as an effective deliberate orientation for ex-juvenile entrepreneurs once they reconsider their delinquent behavior with entrepreneurial autonomous activities. Assuming autonomous orientation looks to replicate a desired reconciliation amongst delinquent behaviors and entrepreneurial autonomous orientation as an alternative to delinquency. Lastly, the conceptual paper concludes with suggesting some inferences for future research to dig out the study theoretically, conceptually and empirically of the individual EO autonomous orientation behaviors among delinquent populace (exjuvenile entrepreneurs) context. This conceptual paper provides a fresh knowledge about the IEO autonomous orientation potentiality in the entrepreneurs' self-development and an insight to the entrepreneurship framework.
\end{abstract}

Keywords: entrepreneurial orientation, ex-juvenile entrepreneurs, delinquent behavioral change, autonomous orientation

\section{Introduction}

Does being autonomous oriented enough to influence ex-juvenile entrepreneurs delinquent behavioral change? Ex-juvenile entrepreneurs are juvenile released from reformatory centers and currently engaging into entrepreneurial activities in Katsina State, Nigeria, which create choices and opportunities for autonomy within the framework of entrepreneurship. The individual entrepreneurial orientation experienced by ex-juvenile entrepreneurs has been clearly described as necessity based entrepreneurial and not opportunity based as the last resort or substitutes for survival because the 
Nigerian government does not provide means (social support or financial support) for the ex-juvenile upon-release.

The lack of other opportunities for engagement also create lack of welfare system to support exjuvenile upon release motivate them create for themselves some means of earnings and livelihood. These push motivation factors drive the ex-juvenile's decision to become entrepreneurs and self-reliant and through their entrepreneurial activities as a means of survival which change their unsafe delinquents' behaviors, and social segregation or even violent reprisal by other delinquents' friends and concentrate on their ventures and its expansion.

Through these initiatives, several individuals in Nigeria are creating their own easy entrepreneurial endeavors due to the lack of other opportunities (Reynolds et al., 2002; Mota, et al., 2019). Thus, through desire for autonomous entrepreneurial activities ex-juvenile entrepreneurs have increased their decision-making autonomous which might be helpful for their business success and delinquent behavioral change. Entrepreneurship orientation (EO) is substantial due to its influence on the economic development, firm's performance and profitability, social change, and trade creation (Goktan \& Gupta, 2015; Klofsten, et al., 2019). Through EO, individual entrepreneurs create value, autonomous orientation individuals seek for freedom decision and financial decision. Building on extant EO theory Lumpkin and Dess, (1996: 140) existing autonomous, the freedom of individuals to practice his/her resourcefulness and champ talented concepts for entrepreneurial progress is an important dimension of a firm's entrepreneurial orientation (EO).

Even though previous research majority established a positive firms EO firms' performance and profitability (Hughes \& Morgan, 2007; Rauch et al., 2009; Debicki, et al., 2016). Subsequently, research revealed that in IEO concept covering multidimensions can be measured together (Lumpkin et al., 2009) or separately (Lumpkin \& Dess, 2001; Wang, 2008), reliant towards the situation. In this study EO dimension autonomous orientation behaviors will be study separately.

Numerous studies revealed positive influence on autonomous including Resource-advantage theory (Jambulingam et al., 2005); organizational identity (Zachary et al., 2011); U-curve theory and life cycle theory (Blut et al., 2011); entrepreneurship orientation (Vora et al., 2012); EO in family firms (Zellweger \& Sieger 2012b); organizational ambidexterity and dynamic capability (Boso et al., 2012); strategic orientation (Boso et al., 2013); EO and competitive strategy (Lechner \& Gudmundsson, 2014); information processing theory (Chen et al. 2015); structural contingency theory (Hakala et al. (2016); EO and marketing orientation (Vega-Vázquez et al., 2016); EO (Peters \& Kallmuenzer 2018b); agency theory and socioemotional wealth (Kallmuenzer et al., 2018); efficient market and incremental useful information perspective (Jancenelle et al. (2017).

Whereas other researchers found autonomous negative impact for example: on subsidiary strategy Taggart (1997); Hofstede's national culture, innovation championing (Shane et al., 1995a); agency theory, resource dependence theory, locus of control and countervailing power premise (Dant \& Gundlach, 1999); EO (Hughes \& Morgan, 2007); a precise model with three phases (Styles \& Genua, 2008); EO in family vs non-family firms Short et al., (2009b); subsidiary EO (Scott et al. (2010) EO; Short et al., (2010). Inconsistently, Porter's theory of competitive (strategy Birkinshaw et al., (2005); International EO, found negative and positive impact (Boso et al., 2017).

Therefore, considering the inconsistent autonomous orientation huge number of research ex-juvenile entrepreneurs' autonomous orientation never explored. less studies conducted on EO at individual level (Kollmann et al., 2014), particularly delinquent populace. The role of the autonomous orientation behaviors on delinquent populace particularly ex-juvenile entrepreneur's business success and their subsequent delinquent behaviors still neglected and illogical. Similarly, ex-juvenile entrepreneurial activities offer a foundation for autonomy as ex-juvenile self-reliance providing a setting where delinquent behavioral change, security safety of the society as well as smooth integration into the society can be apprehended, this resulting to autonomous decision freedom on their entrepreneurial activities and financial freedom (Edelman et al., 2010; Stephan et al., 2015). 
Even though, ex-juvenile entrepreneur's autonomous orientation behaviors deliver a fertile ground setting where trust and decent behavior can flourish amongst their immediate community, leading to smooth integration and higher levels of autonomous decision making towards their entrepreneurial success. Henceforth, it has been established that autonomous is important to the long run success that furthermost individuals' and firms pursue (Burgelman, 2001; Lumpkin et al., 2010), still never explored the influence of autonomous orientation behaviors on delinquent behavioral change and people behavioral change in broader term.

Therefore, in this study we are mainly interested on how individual EO autonomous orientation behavior can influence ex-juvenile entrepreneurial activities and subsequently, influence ex-juvenile entrepreneurs delinquent behavioral change, which to the best of our knowledge never be explored. Even though, existing literature on delinquent's populace discovered, majority of the studies largely centered on the prison entrepreneurship programs towards adult prisoners and reflected inconsistent findings (Downing 2012; Soloman, 2012). Accordingly, researches on delinquent populace found that approximately prisoners partake entrepreneurial talent and potentiality for entrepreneurship (Sonfield, 2010 ; 2013). Therefore, the empirical literature in the context of ex-juvenile entrepreneurs is limited and ambiguous precisely in developing countries like Nigeria.

\section{Literature Review}

There are several empirical studies on entrepreneurial autonomous in areas dealing with delinquent entrepreneurship resulted from prisons entrepreneurship programs (Sonfield, 2008; Downing 2012; Soloman, 2012; Sonfield, 2013). Basically, Prison Entrepreneurship Programs influence prisoners to have entrepreneurial aptitude and potentiality for entrepreneurial success (Sonfield, 2001). Furthermore, Sonfield (2013) revealed that, $8 \%$ drop of delinquency rates also save the social order by 5 times the programs expenses. In view of the entrepreneurship orientation literature, ex-juvenile entrepreneurial autonomous orientation behaviors research is entirely missing or not surfacing. What is absent in the literatures is the discussion on how autonomous can influence towards ex-juvenile entrepreneur's delinquent behavioral change. Resulting in lack of significant studies conducted on exjuvenile entrepreneurs in Katsina state, Nigeria. Considering most of the studies concentrate on adult prisoners none study on ex-juvenile entrepreneurs' business success surface so far, and autonomous orientation behaviors on ex-juvenile entrepreneur's delinquent behavioral change. Therefore, this study conceptually examines the influence of single IEO dimension; autonomous orientation behaviors towards ex-juvenile entrepreneurs towards delinquent behavioral change. Within entrepreneurial context, autonomous orientation is about 'the decision freedom, financial freedom and develop and enact entrepreneurial initiatives' (Lumpkin et al., 2009: Pp 47). Because of its significance to new venture development and entrepreneurial value creation. (Lumpkin and Dess, 1996; Burgelman, 1983; 2001) claimed that, it is a 'crucial' dimension of EO (Pp. 141), specifically autonomous to define hitches and chances, established priorities regarding these problems and the policymakers to take actions to offer resolutions.

Autonomous Orientation can be seen as Decision freedom, Enacting entrepreneurial initiative and Financial freedom (Lumpkin \& Dess, 1996; Callaghan \& Venter, 2011). Autonomous orientation has not been commonly discovered in the existing of entrepreneurship researches (Lumpkin et al., 2009; Short et al., 2009). It has established less studies, in part, because the original EO conceptualization (Miller, 1983) and measurement scales (Covin \& Slevin, 1989) absent of autonomous orientation. Nonetheless, there are substantial theoretical and empirical backing for the significance of autonomous orientation behaviors to entrepreneurial activities success. Despite its importance, the theoretical behavior of entrepreneurial independence surface, with slight theorizing relating to the concept. Autonomous orientation is generally related to individuality, freedom, and influence (Lange, 2012), taking affairs (Stephan et al., 2015), and suppleness (Edelman et al., 2010; Jayawarna, et al., 2013).

These parts state to decision freedom concerning when effort is done, correspondingly. These types of autonomy are applied to business owners and research revealed that autonomous is the reason individuals initiate, and manage own business (Stephan et al., 2015). According to Lumpkin and Dess, 
(1996) autonomous orientation drew from the two viewpoints, recognizing its significance for entrepreneurship its role in new entry by business owners. The later theme about entrepreneurs is specifically significant when bearing in mind autonomy in the background of ex-juvenile entrepreneurs. The importance of EO, autonomous is also applied in management literature in the context of autonomous (Taggart, 1997). Taking decision freedom concerning how, when and what business decision will be done concerning strategy situation direction of the venture (Lumpkin et al., 2009).

In addition, researches established that, Uncertainty evading was negatively related to autonomy (Shane et al., 1995a). Likewise, Taggart (1997) revealed that, autonomous and practical justice are used to form four types of subsidiaries. Dant and Gundlach (1999) suggest that, Competition is low desire of franchisees for autonomous. Autonomous is not significantly related to product performance or customer performance, suggesting no business performance value at this very young stage of firm growth (Hughes \& Morgan, 2007). Similarly, Styles and Genua (2008) Autonomous orientation not necessities to all entrepreneurial activities. Also, Short et al. (2009b) related to non-family businesses, family businesses have lower levels of autonomy.

The same, Autonomy has no significant impact on Tobin's Q (Short et al., 2010). Lastly, Scott et al. (2010), EO unidimensional at the subsidiary unit fully mediates the effect of subsidiary autonomy on strategy creativity, initiative and performance. No direct impact is from autonomy on the three dependent variables. Contrary, Jambulingam et al. (2005) found that, Autonomous is high in the clusters of 'true entrepreneurs' is higher and low risk entrepreneurs.

Cochet et al. (2008), revealed that, Franchisee autonomous is significantly positive related to relational governance and is moderated by number of outlets, franchisee success and intra-chain competition. Again, Zachary et al. (2011), they discovered, 500 Franchise have significant higher levels of autonomous. Also, Blut et al. (2011) discover U-shaped level of autonomous, with highly autonomous throughout honeymoon and steadiness periods, and lower levels during monotonous and crossroad periods. Also, Vora et al. (2012) exposed that, employee stock option program and flat organizational structure are key organization objects that enable autonomous. Zellweger and Sieger (2012b) high levels of external autonomous are more emphasized. Likewise, when later generations join the business, internal autonomy increases. Boso et al. (2012) spread autonomous behaviors are part of the score of an overarching EOB construct.

Equally, Boso et al. (2013) show that Autonomous is part of the complex cut of a predominant EO dimension. Autonomy is positively related to sales increase is significantly positive with profitability. Again, autonomous is positively impact on differentiation but a negative impact on cost leadership (Lechner \& Gudmundsson, 2014). Both differentiation and cost leadership have a significant positive impact on firm performance but no direct impact from autonomous towards performance. Also, there is positive relation between development cost, product success and expansion speed (Chen et al., 2015). It was established that, decision freedom is a borderline condition of EO to international new entrance, (Hakala et al., 2016). Equally, Vega-Vázquez et al. (2016) suggest that, autonomous orientation is one of the influential issues of predominant EO concept. Jancenelle et al. (2017) revealed that, autonomy is the most significant finding in this study, confirming the cues of autonomy have positive impact on the same-day stock price. Kallmuenzer et al. (2018) found that, For the main effect, autonomy has marginally and significantly positive impact on performance. Regarding contingency effect, autonomy interacting with control mechanisms positively affects performance. Peters and Kallmuenzer (2018b), Autonomy as positive and important traits to successfully run a family business. External autonomy is considered more present in family firms than internal autonomy. Also, no sign indicates autonomy is becoming less important over generations or shifts from external to internal autonomy

Inconsistently, empirical research revealed mixed reaction about the influence of autonomous influence, Jancenelle, et al. (2017) found positive influence on performance, also Chen, et al. (2015), found positive autonomy influence towards business performance. Contrary, negative significance influence between autonomous and business performance by Hughes and Morgan (2007) found. Similarly, research found no significance relationship between autonomous and performance (Lechner 
\& Gudmundsson, 2014). EO, autonomy assume in its fundamental theoretical statement that higher levels of EO, in proper formations with other key factors such as environment, might influence performance positively Rauch et al.'s (2009). Rauch et al. (2009), propose relationships to performance are possible composite and may be issue to situations in the business background. Therefore, autonomous orientation is rather inconsistent and ambiguous research finding (Zellweger \& Sieger, 2012; Jancenelle, et al. 2017). Subsidiaries internally attentive on competitive environments is rather low autonomous than externally competitively focused. According to Boso et al. (2017) absorptive competence and knowledge-based opinion Autonomous is correlated negatively with expansion regional. As autonomy interacts with channel management capability, the effect to regional expansion turns positive and stronger autonomous freedom encourages entrepreneurial activities satisfaction and success. Existing research revealed that entrepreneurs viewed as related autonomous.

Despite the fact, considerable difference happens, satisfaction level comparing to their workers to the extent to be explained by the increasing of autonomous they exercise (Lange, 2012; Stephan, 2018). The business owners could be in switch in the interior of the business then might be applied in a risky location; business partners will want to have their opinion, and uncertainty about growths in the business setting can be severe. Van Gelderen (2016) also revealed that self-reliance is important to autonomous; entrepreneurs frequently autonomously decide to briefly sacrifice their autonomous; this is then meant to be temporary. So, the paper concluded that autonomous is not only about exercised decision freedom, but also about whether the existing level of experienced decisional freedom is selfdetermined. Autonomous has not been explored in the context connected to companies and their workers, with the emphasis actuality on the employees rather than ex-juvenile entrepreneurs.

In summary, EO, autonomous orientation numerous researches have established that autonomous has been positively influence to business performance (Awang et al., 2009). Nevertheless, additional researchers do not believe such impressions for instance (Hughes \& Morgan, 2007; Casillas \& Moreno, 2010). Nevertheless, none of these studies linked autonomous influence towards delinquent behavioral change therefore, autonomous orientation behaviors can have influence towards ex-juvenile entrepreneurs is not yet explored. The varied nature of autonomous influence displayed the need to expand knowledge about this influence and relationship of autonomous orientation towards exdelinquent populace. Despite the fact that theorizing on business autonomous is scanty from the literature, important consideration has been specified to the autonomy of workforces.

Therefore, self-employment as opposed to employment by others offers a possible alternative for exdelinquent and a possible approach in decreasing recidivism rate. it can be shown that ex-delinquent does indeed may have skills for entrepreneurship, then arguments can be made for the implementation of autonomous orientation behaviors for the ex-juvenile entrepreneurs, as it is certainly in society's top safeties for ex-delinquents to secure a job. In view of the delinquent's entrepreneurship orientation autonomous dimension' literature, ex-juvenile entrepreneurial autonomous orientation behaviors research is entirely missing or not surfacing. So, in this study we proposed to explore the autonomous orientation behaviors that can have influence towards Ex-juvenile entrepreneurs' delinquent behavioral change for the first time (see figure 1) therefore, this led to the question that, how does autonomous orientation behaviors influence ex-juvenile entrepreneurial success and their subsequent delinquent behavioral change? And thus, we propose the following proposition:

\section{Proposition: Autonomous orientation behaviors influence towards ex-juvenile entrepreneurs' delinquent behavioral change}

The existing individual entrepreneurial orientation autonomous orientation literature, the autonomous is well-defined countlessly. Three different indicators exist: Decision freedom, financial freedom and enacting entrepreneurial initiatives Lampkin and Dess (1996) it is very vital to link these indicators to the autonomous orientation behaviors. The proposition of EO autonomous orientation is a mixture of these indicators. The prevailing literature on the topic of autonomous orientation do not introduce in an explicit manner, autonomous as such. Autonomous is a unique perception in entrepreneurship orientation literature. Figure 1, adapted from (Lumpkin and Dess) describes the position of autonomous 
orientations and its influence towards delinquent behavioral change. Of importance in figure 1 is that autonomous orientation can influence ex-juvenile entrepreneurs' delinquent behaviors by adopting an autonomous to reinforce its decision freedom, financial freedom and entrepreneurial initiatives. Exjuvenile entrepreneurs that adopt an autonomous orientation behavior that center on their entrepreneurial activities can that can influence their delinquent behaviors than those ex-juveniles that do not adopt it. Moreover, ex-juvenile that center on autonomous entrepreneurial orientation activities can be more likely to delinquent behavioral than their counterpart who do not adopt autonomous orientation.

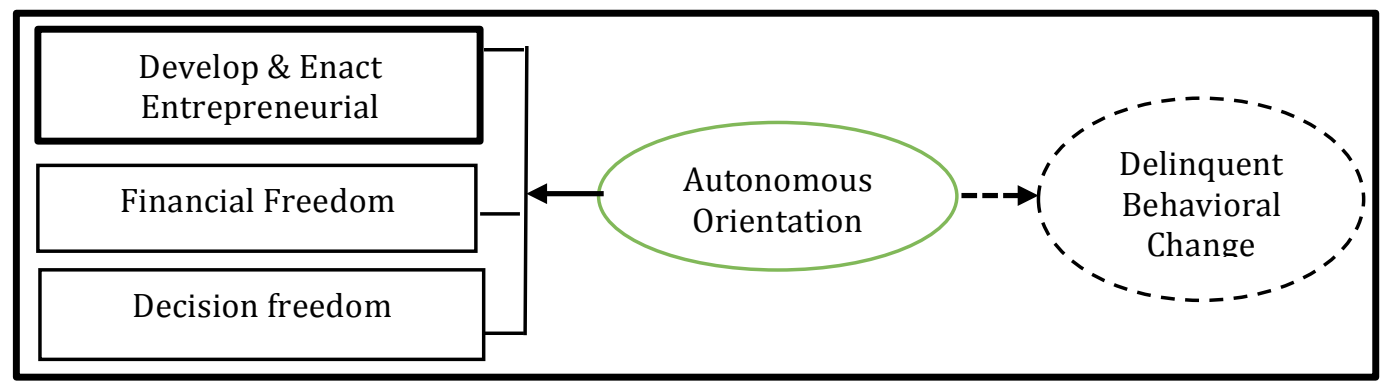

Figure 1: Proposed autonomous orientation influence on delinquent behavioral change

\section{Conclusion}

The study discusses on autonomous orientation behaviors influence towards ex-juvenile entrepreneurs' delinquent behavioral change. This conceptual paper illustrates the influence of autonomous orientation on ex-juvenile entrepreneurial activities and their subsequent delinquent behavioral change. We conclude that autonomous orientation behaviors are very essential to ex-juvenile entrepreneurial activities and delinquent behavioral change since they do not apply theories while engaging into entrepreneurial autonomous behavior. This conceptual paper is the first to the conceptualize autonomous orientation influence on ex-juvenile entrepreneurial activities and ex-juvenile subsequent delinquent behavioral change. Thus, we provide new insight on ex-juvenile entrepreneurs for study autonomous orientation behavior. Our frame work extends the concept of autonomous orientation which focuses on individual entrepreneurs.

The paper concludes that, ex-juvenile entrepreneur's autonomous orientation behaviors might influence their delinquent behavioral change and decisions freedom and financial freedom towards their entrepreneurial activities. By understanding autonomous orientation that encourage entrepreneurial behaviors we substantiate the importance of consistency of autonomous orientation behaviors influence entrepreneurial activities among ex-juvenile entrepreneurs. The concept of IEO autonomous orientation behaviors can be understood in terms of decision freedom, financial freedom, and enacting of entrepreneurial activities Lumpkin and Dess (1996). The role of autonomous dimension remains important for the entrepreneurial activities as a constant to be managed and joined in business development and subsequent delinquent behavioral change. The links between IEO autonomous orientation and other dimensions on delinquent populace (ex-juvenile entrepreneurs) shall be discovered for further study.

Then, future research employing the other EO dimensions and Entrepreneurial lookouts should demonstrate fertile in detecting the extent and situations to which each IEO dimension lookout restored apprehensions the relative position of the autonomous orientation influence towards delinquent behavioral change and custody rationalized the business opportunities and prosperous capabilities. These vantage point will inspire the debate on the spectacle and revisit the conceptualization of autonomous. The literature shows entrepreneurship can be a multidimensional concept with five dimensions: autonomous, innovation, risk-taking, competitiveness and proactiveness (Miller, 1983; Covin and Slevin, 1986; 1989). The multidimensions of EO may also be vary individualistically (Kreiser et al, 2002; Lumpkin \& Dess, 1996; Stetz et al., 2000). 
Furthermore, we make new contributions to the concept of autonomous orientation based the application of this framework of autonomous orientation by demonstrating that autonomous can influence ex-juvenile entrepreneurial activities success and also can influence autonomous on exjuvenile entrepreneurs' delinquent behavioral change. This means the application of this framework will be relevant to ex-juvenile entrepreneurs who wish to improve performance, especially ex-juvenile entrepreneurs in Katsina state Nigeria who might consider entrepreneurial autonomous as alternative framework to better enhance entrepreneurial activities and delinquent behavioral change than applying models. The conceptual framework guide policy makers, autonomous orientation analyst to develop policies and programs to improve the ex-juvenile entrepreneurial activities, as well as autonomous orientation behaviors as new paradigm. The framework provides insight to ex-juvenile entrepreneurs on proper application of how their autonomous orientation behaviors can negatively or positively influence entrepreneurial activities and delinquent behavioral change. Overall, our framework is a novelty and can contribute to higher performance of ex-juvenile entrepreneurial activities.

Consequently, the measurement will be applied for IEO and replicate the ex-juvenile entrepreneur's autonomous orientation behavior reflecting the willingness of an ex-juvenile entrepreneurs to engage in entrepreneurial autonomous behaviors. As for future study methodology in the future, qualitative approach in-depth interviews to measurement of EO autonomous orientation may be the preferred measure, and may provide a deep considerate of the ex-juvenile entrepreneurial orientation behaviors (Tijjani et al., 2009: Mohamad \& Perry, 2015).

\section{References}

Birkinshaw J, Hood N and Young S (2005) Subsidiary Entrepreneurship, Internal and External Competitive Forces, and Subsidiary Performance. International Business Review 14(2): 227248.

Blut M, Backhaus C, Heussler T, et al. (2011) What to Expect After the Honeymoon: Testing a Lifecycle Theory of Franchise Relationships. Journal of Retailing 87(3): 306-319.

Boso N, Cadogan JW and Story VM (2012) Complementary Effect of Entrepreneurial and Market Orientations on Export new Product Success Under Differing Levels of Competitive Intensity and Financial Capital. International Business Review 21(4): 667-681.

Boso N, Oghazi P and Hultman M (2017) International Entrepreneurial Orientation and Regional Expansion. Entrepreneurship and Regional Development 29(1-2): 4-26.

Boso N, Story VM and Cadogan JW (2013) Entrepreneurial orientation, market orientation, network ties, and performance: Study of entrepreneurial firms in a developing economy. Journal of Business Venturing 28(6): 708-727.

Burgelman RA (2001) Strategy Is Destiny: How Strategy-Making Shapes a Company's Future. New York: The Free Press.

Chen J, Neubaum DO, Reilly RR, et al. (2015) The Relationship Between Team Autonomy and New Product Development Performance Under Different Levels of Technological Turbulence. Journal of Operations Management 33: 83-96.

Covin JG and Slevin DP (1989) Strategic Management of Small Firms in Hostile and Benign Environments. Strategic Management Journal 10: 75-87.

Covin, J. G. and Slevin, D. P. (1986). The Development and Testing of an organizational-level Entrepreneurship Scale. Frontiers of Entrepreneurship Research. Babson College.

Covin, J. G. and Slevin, D. P. (1989). Strategic Management of Small Firms in Hostile and Benign Environment. Strategic Management Journal, Vol.10: 75-87.

Dant RP and Gundlach GT (1999) The Challenge of Autonomy and Dependence in Franchised Channels of Distribution. Journal of Business Venturing 14(1): 35-67.

Debicki, B. J., Kellermanns, F. W., Chrisman, J. J., Pearson, A. W., \& Spencer, B. A. (2016). Development of a Socioemotional Wealth Importance (SEWi) Scale for Family Firm Research. Journal of Family Business Strategy, 7(1), 47-57.

Downing, C. (2012). Bolivian Prison Entrepreneurship: An Unexpectedly Successful Rehabilitation Method. Journal of Enterprising Communities: People and Places in the Global Economy, 6(4), 339-349. 
Edelman, D. C. (2010). Branding in the digital age. Harvard business review, 88(12), 62-69.

Goktan, A.B. and Gupta, V.K. (2015), "Sex, Gender, and Individual Entrepreneurial Orientation: Evidence from Four Countries", The International Entrepreneurship and Management Journal, Vol. 11 No. 1, pp. 95-112.

Hakala H, Sirén C and Wincent J (2016) Entrepreneurial Orientation and International New Entry: The Moderating Role of Autonomy and Structures in Subsidiaries. Journal of Small Business Management 54: 90-112.

Hughes M and Morgan RE (2007) Deconstructing the Relationship Between Entrepreneurial Orientation and Business Performance at the Embryonic Stage of Firm Growth. Industrial Marketing Management 36: 651-661.

Ingram AE, Lewis MW, Barton S, et al. (2016) Paradoxes and Innovation in Family Firms: The Role of Paradoxical Thinking. Entrepreneurship Theory and Practice 40(1): 161-176

Jambulingam T, Kathuria R and Doucette WR (2005) Entrepreneurial Orientation as a Basis for Classification Within a Service Industry: The Case of Retail Pharmacy Industry. Journal of Operations Management 23(1): 23-42.

Jancenelle VE, Storrud-Barnes S and Javalgi RRG (2017) Corporate Entrepreneurship and Market Performance: A Content Analysis of Earnings Conference Calls. Management Research Review 40(3): 352-367.

Jancenelle VE, Storrud-Barnes S and Javalgi RRG (2017) Corporate Entrepreneurship and Market Performance: A content analysis of Earnings Conference calls. Management Research Review 40(3): 352-367

Jancenelle VE, Storrud-Barnes S and Javalgi RRG (2017) Corporate Entrepreneurship and Market Performance: A Content Analysis of Earnings Conference Calls. Management Research Review 40(3): 352-367

Jayawarna, D., Rouse, J., \& Kitching, J. (2013). Entrepreneur motivations and life course. International small business journal, 31(1), 34-56.

Kallmuenzer A, Strobl A and Peters M (2018) Tweaking the Entrepreneurial Orientation-Performance Relationship in Family Firms: The Effect of Control Mechanisms and Family-Related goals. Review of Managerial Science 12(4): 855-883.

Kollmann, T., \& Stöckmann, C. (2014). Filling the Entrepreneurial Orientation-Performance Gap: The Mediating Effects of Exploratory and Exploitative Innovations. Entrepreneurship Theory and Practice, 38(5), 1001-1026.

Kreiser, P.M., Marino, L. and Weaver, M. (2002). Correlates of Entrepreneurship: The Impact of National Culture on Risk-Taking and Proactiveness in SMEs. 16th Annual USASBE National Conference, (www.usasbe.org/)

Lechner C and Gudmundsson SV (2014) Entrepreneurial Orientation, Firm Strategy and Small Firm Performance. International Small Business Journal 32(1): 36-60.

Lumpkin GT and Dess GG (1996) Clarifying the Entrepreneurial Orientation Construct and Linking it to Performance. Academy of Management Review 21(1): 135-172.

Lumpkin GT and Dess GG (2001) Linking Two Dimensions of Entrepreneurial Orientation to firm Performance: The Moderating role of Environment and Industry Life Cycle. Journal of Business Venturing 16(5): 429-451.

Lumpkin GT, Brigham KH and Moss T (2010) Long-term Orientation: Implications for the Entrepreneurial Orientation and Performance of family businesses. Entrepreneurship and Regional Development 22(3-4): 241-264.

Lumpkin GT, Cogliser CC and Schneider DR (2009) Understanding and Measuring Autonomy: An Entrepreneurial Orientation Perspective. Entrepreneurship Theory and Practice 33(1): 47-69.

Lumpkin, G. T. and Dess, G. G. (1996). Clarifying the Entrepreneurial Orientation Construct and Linking it to Performance. Academy of Management Review, 21(1): 135-172.

Miller, D. (1983). The Correlates of Entrepreneurship in Three Types of Firms. Management Science, Vol.29, 7: 770-791.

Mota, A., Braga, V., \& Ratten, V. (2019). Entrepreneurship Motivation: Opportunity and Necessity. In Sustainable Entrepreneurship (pp. 139-165). Springer, Cham.

Peters M and Kallmuenzer A (2018) Entrepreneurial Orientation in Family Firms: The Case of the Hospitality Industry. Current Issues in Tourism 21(1): 21-40. 
Rauch A, Wiklund JW, Lumpkin GT, et al. (2009) Entrepreneurial Orientation and Business Performance: An Assessment of Past Research and Suggestions for the Future. Entrepreneurship Theory and Practice 33(3): 761-781.

Reynolds, P., Bygrave, W., Autio, E., Cox, L. and Hay, M. (2002), Global Entrepreneurship Monitor: 2002 Executive Report, Ewing Marion Kauffman Foundation, Wellesley, MA.

Scott P, Gibbons P and Coughlan J (2010) Developing Subsidiary Contribution to the MNC Subsidiary Entrepreneurship and Strategy Creativity. Journal of International Management 16(4): 328-339.

Shane S, Venkataraman S and MacMillan I (1995) Cultural Differences in Innovation Championing Strategies. Journal of Management 21(5): 931-952.

Short JC, Broberg JC, Cogliser CC, et al. (2010) Construct Validation Using Computer-aided Text analysis (CATA): An Illustration Using Entrepreneurial Orientation. Organizational Research Methods 13(2): 320-347.

Short JC, Payne TG, Brigham KH, et al. (2009) Family firms and Entrepreneurial Orientation in Publicly Traded Firms: A Comparative Analysis of the S\&P 500. Family Business Review 22(1): 9-24.

Solomon, A. L. (2012). In Search of a Job: Criminal Records as Barriers to Employment. NIJ Journal, $270,42-51$.

Sonfield, M. (2013). Entrepreneurship Training and Prisoner Re-Entry: Lessons from a Successful Program. Small Business Institute, 91.

Sonfield, M. C. (2008). Entrepreneurship and Prisoner Re-entry: The Development of a Concept. Small Business Institute Research Review, 35.

Sonfield, M., Lussier, R., \& Barbato, R. (2001). The Entrepreneurial Aptitude of Prison Inmates and the Potential Benefit of Self-employment Training Program. Academy of Entrepreneurship Journal, 7(2), 85-94.

Stephan U and Uhlaner LM (2010) Performance-based vs Socially Supportive Culture: A CrossNational Study of Descriptive Norms and Entrepreneurship. Journal of International Business Studies 41(8): 1347-1364.

Stephan, U., Uhlaner, L. M., \& Stride, C. (2015). Institutions and social entrepreneurship: The role of institutional voids, institutional support, and institutional configurations. Journal of International Business Studies, 46(3), 308-331.

Stetz, P. E., Stewart, A., Howell, R, Blair, J. D. and Fottler, M.D. (1998). Dimensionality of the Entrepreneurial Posture/Orientation Construct: A Structural Equation Study. The Academy of Management Meeting, San Diego CA.

Styles C and Genua T (2008) The Rapid Internationalization of High Technology Firms Created Through the Commercialization of Academic Research. Journal of World Business 43(2): 146157.

Taggart JH (1997) Autonomy and Procedural Justice: A framework for Evaluating Subsidiary Strategy. Journal of International Business Studies 28(1): 51-76.

Vega-Vázquez M, Cossío-Silva FJ and Revilla-Camacho MÁ (2016) Entrepreneurial OrientationHotel Performance: Has Market Orientation Anything to say? Journal of Business Research 69(11): 5089-5094.

Vora D, Vora J and Polley D (2012) Applying Entrepreneurial Orientation to a Medium Sized firm. International Journal of Entrepreneurial Behavior and Research 18(3): 352-379.

Wang, C. L. (2008). Entrepreneurial orientation, learning orientation, and firm performance. Entrepreneurship theory and practice, 32(4), 635-657.

Zachary MA, McKenny AF, Short JC, et al. (2011) Franchise Branding: An Organizational Identity Perspective. Journal of the Academy of Marketing Science 39(4): 629-645.

Zellweger T and Sieger P (2012) Entrepreneurial Orientation in Long-Lived Family Firms. Small Business Economics 38(1): 67-84. 